\title{
Blind faith
}

\section{Many believe that double-blind peer review reduces referee bias, real or perceived.}

Beginning this month, this journal (along with our sister journal Nature Geoscience) is going to trial - as an option to authors - double-blind peer review. Under this system, reviewers will keep their anonymity, as before, but they will not be told whose work it is that they are being asked to review. This contrasts with the single-blind peer review process currently used by the Nature family of journals, including Nature Climate Change, under which reviewers know whose work it is that they are looking at.

Anonymity allows referees to comment candidly on research without undue fear of social or professional reprisal. However, if they know the identity of authors, there is at least the possibility of reviewer bias. This could be for reasons of perceived reputation, competitiveness, seniority, nationality, gender, ethnicity or a whole host of other factors that can easily be gleaned from a manuscript's author list. Most referees - we trust and believe - try to be objective in their assessments, and are not swayed by factors associated with authorship. But simply withholding author information should largely remove the possibility of such bias, whether conscious or not. In so doing, this double-blind process has the potential to make scientific peer review, well, more scientific - or so many critics of conventional single-blind review assert.

We are aware, of course, that doubleblind peer review also has some possible shortcomings. Some candidate referees may be reluctant to review manuscripts of unknown provenance; others may in any case know, or correctly guess the authors' identities from the nature of the research under review. Nor can we be sure that double-blind review will make any practical difference in terms of final editorial decisions.

It is also important to stress that the double-blind peer review trial will not be run as a controlled experiment.
Participation will not be mandatory, which necessarily means that participating authors will be a self-selected group. We hope, however, that uptake will be good and that the trial will indicate the possible benefits of double-blind review.

There will in due course be a new section of our guide to authors to explain the process, but it will actually be very straightforward. When submitting a manuscript through our website, authors will need to select the option 'Yes I do want to participate in double-blind peer review'. This will prevent authorship and contact information being transmitted to referees. Obviously, authors will also need to ensure that none of the uploaded files contain information that would inadvertently reveal their identity. Details of what to exclude will also be listed in the guide. We hope you will appreciate having this option, and we will be monitoring uptake and soliciting your feedback over coming months.

\section{Positive intentions}

\section{Countries met again at a new climate change meeting, but this time to work out solutions.}

The latest round of United Nations (UN) climate talks, held in Bonn from 29 April to 3 May this year, was pervaded - for the first time in years - by a good feeling. A sense of moderate optimism grew among the more than 1,000 participants discussing the efforts to curb emissions and drive green growth that should be mobilized by the international climate treaty expected in 2015. In the words of the executive secretary of the UN Framework Convention on Climate Change, Christiana Figueres, "Countries discussed concrete solutions to speed up and scale up action". This is not to say that they converged on the need to set new and more stringent binding national emissions caps in 2015, but they definitely joined the roundtable with a much more cooperative disposition than in the past.

Cooperation, however, did not extend to all of the discussions that took place in Bonn. In fact, the contention between developed and developing countries about sharing the burden of emissions mitigation was still marked. It has long been debated - including at the Conference of the Parties in Doha last December - whether industrialized countries responsible for historical emissions should continue to bear the largest proportion of mitigation costs in the future. The most contested view is that poor and emerging economies are increasing carbon emissions and therefore should intensify their efforts to mitigate. This is certainly opposed by developing countries, such as the Philippines, for example, whose interests were firmly defended in Bonn by its charismatic negotiator Bernaditas de Castro Müller. She made a strong call for rich nations to reduce their carbon footprint when poor countries have very limited resources and struggle with the effects of climate change.

The international community has to support developing nations as poverty undoubtedly increases susceptibility to climate-related risks. But vulnerability to climate change has several dimensions that depend on a combination of economic and social factors. A social condition important in the context of climate risks is gender, another issue tabled at the talks in Bonn. The perspective seemed to be that women are at greater risk from climate change than men because of their role in supporting families, especially in less-developed countries, which often means having to secure water, fuel and food. But women's exposure to climate impacts is not simply a threat to households, as Bangladeshi representative for UN Women (a recent UN initiative for gender equality), Christine Hunter, pointed out at the 7th International Conference on Community-based Adaptation to Climate Change a few days before the talks in Bonn began. She felt that the debate is rarely on women's own rights and that "Rights focus on people... who can drive their own development". Future climate negotiations should build on these discussions, and will hopefully embrace a rights-based approach to limit the vulnerability of human societies to climate change. 